\title{
Attempted Development of a Clinical Decision- making Model to Assist in Femoral Neck Stress Fracture Screening in Military Trainees
}

Justin S Zimmerman ( $\sim$ justin.s.zimmerman@gmail.com )

Carl R Darnall Army Medical Center https://orcid.org/0000-0002-1723-3279

Gail D. Deyle

Brook Army Medical Center

Mark E Lester

Army-Baylor Doctoral Program in Physical Therapy

Jamie B Morris

PRO Physical Therapy: ATI Physical Therapy

Christopher S Allen

University of Cincinnati College of Allied Health Sciences

Research

Keywords: femoral neck, stress fracture, prediction, military trainees, diagnosis, imaging

Posted Date: November 2nd, 2020

DOl: https://doi.org/10.21203/rs.3.rs-99439/v1

License: (9) This work is licensed under a Creative Commons Attribution 4.0 International License. Read Full License 


\section{Abstract}

Background: Femoral neck stress fractures (FNSF) are serious injuries prevalent throughout the military, particularly within the initial entry training (IET) population. Delay in diagnosis and management can lead to complications secondary to fracture progression and displacement. Effective screening and identification of FNSF can reduce patient risk, mitigate costs associated with treatment, and prevent the potential medical discharge of IET personnel. There is currently no validated testing to assist in decisions for ordering advanced imaging to rule out FNSF. Military healthcare providers, therefore, must rely on advanced imaging of patients with hip region complaints to rule out suspected FNSF resulting in potential MRI over utilization. The purpose of this project was to determine if a clinical decision model can be developed from clinical findings to assist clinicians in deciding when magnetic resonance imaging (MRI) is warranted for FNSF screening in IET personnel with hip or groin pain.

Methods: This was a prospective observational cross-sectional cohort process improvement project. We screened all IET Soldiers presenting to a medical clinic with hip or groin pain and evaluated 18 clinical variables. The reference standard was a FNSF diagnosed using fast-sequence MRI. Statistical analyses included correlation, receiver operating characteristic (ROC) curve assessments, and regression.

Results: Final statistical analysis included 184 IET Soldiers, of which 49 had a FNSF. Frequency analysis observed the highest occurrence of FNSF in non-Hispanic white females. Ten subjective and physical examination variables had a weak correlation to positive MRI findings for FNSF. Regression analysis revealed six variables with positive MRI outcome predictive abilities; however, small to medium effect sizes, low ability to account for MRI outcome variance, and poor estimated sensitivity on ROC curve analysis limit this regression model's clinical usefulness utilizing the identified variables.

Conclusions: The regression models evaluating the clinical variables within this project failed to demonstrate adequate predictability and clinical usefulness when screening for the high-risk injury FNSF in an IET population. Clinicians should maintain a low threshold for ordering an MRI to screen for FNSF in this population. Clinicians also cannot rely on subject-reported pain locations or objective testing as definitive assessment signs to distinguish between IET Soldiers with and without a FNSF.

Trial Registration: This study was deemed as a process improvement project by the Brooke Army Medical Center Institutional Review Board on 7 August 2017. A trial registration was not needed.

\section{Background}

Healthy, capable, and fully trained personnel are vital to military readiness. Overuse injuries can lead to a substantial loss in training time, ${ }^{1-4}$ increased healthcare costs, ${ }^{1,3,5}$ and potential long-term morbidity. ${ }^{6-8}$ Early identification and effective treatment are essential to maintaining a ready force.

Military recruits have a higher risk for stress fractures ${ }^{1,4,9-11}$ compared to military non-recruits ${ }^{4}$ or civilians. ${ }^{9}$ The incidence of lower extremity stress fractures in military recruits is estimated to be as high 
as $21 \% .{ }^{10}$ Femoral neck stress fractures (FNSF) make up between $2-10 \%$ of all lower extremity stress fractures in military recruits and may have the greatest potential for long-term complications. $4,7,10,12$ Sequelae of femoral neck stress fractures include fracture displacement, avascular necrosis, and in the most severe cases may require total hip arthroplasty. $5,7,13,14$ In a retrospective study, Chalupa et al. reported that $66 \%$ of initial entry training (IET) Soldiers who required surgical fixation and $48 \%$ who underwent nonsurgical care for FNSF could not return to full training, resulting in a medical discharge. ${ }^{5}$ Timely, accurate identification of these serious injuries may reduce the risk of fracture progression and associated sequelae. ${ }^{8,15}$

Early diagnosis of FNSF can be challenging. Because clinical presentation is variable and physical examination is of questionable utility, ${ }^{16,17}$ the current diagnostic process for FNSF relies almost exclusively on imaging. ${ }^{7,17-19}$ Radiographs are specific diagnostic tests ${ }^{19,20}$ and may identify stress fractures in the advanced stages, ${ }^{16,20}$ but are not typically sufficiently sensitive to screen for FNSF. $7,16,17,20$ Fast-sequence magnetic resonance imaging (MRI) is an alternative to traditional sequence MRI studies. ${ }^{6,7}$ Fast-sequence T1-weighted MRI has a sensitivity and specificity greater than $99 \%$ for diagnosing a fracture, avascular necrosis, or muscle injuries in the hip or pelvic regions, making this the screening modality of choice when available ${ }^{6,7,21}$ Fast sequence hip MRI is capable of completing examinations within $10 \mathrm{~min}$, as compared to normal sequence MRI which can take up to 40 minutes without contrast. 6,7

The intent of this project was to evaluate the utility of single and combined history and examination items in determining when a FNSF should be considered in the differential diagnosis of IET Soldiers with hip or groin pain, thus warranting an MRI. The goal is to improve clinical screening decisions resulting in timely diagnosis of FNSF without unnecessary imaging procedures. We hypothesized that a cluster of commonly reported variables will predict FNSF in military recruits using fast-sequence MRI as the diagnostic gold standard.

\section{Methods}

The institutional review board at Brooke Army Medical Center (BAMC) approved this design as a process improvement project. All participating physical therapists completed a 1-hour training session on the project intent and data collection procedures. Physical therapists collected examination information on IET Soldiers seeking care for hip or groin pain at two different clinics at Joint Base San Antonio - Fort Sam Houston, TX. One clinic was a direct access physical therapy clinic and the other a troop medical clinic. This allowed IET personnel the flexibility to see a physical therapist directly or go to a medical clinic where they would be screened by one or more medical personnel for their complaints. Personnel seen at the medical clinic were managed by a primary care provider, but a physical therapist involved in the study performed all data collection. IET personnel presenting to either clinic with hip or groin pain were determined to be suitable to participate if they did not have contradictions for an MRI examination or a history of orthopaedic hip or pelvic surgery. 
Following arrival at one of the two clinics, IET Soldiers meeting inclusion criteria completed a health screening form (Appendix 1) that assessed individual subjective information described in the literature as potentially related to the presence of FNSF. Each evaluating therapist, regardless of clinic, performed an examination based on the Soldier's presenting symptoms and history. While providers tailored the examination to the Soldier's complaint, signs, and symptoms, there was a standardized portion of the examination specific for data collection purposes (Appendix 2). For IET Soldiers under the care of other providers in the troop medical clinic, the physical therapist only collected project data and recorded the clinical processes for screening IET Soldiers with suspected FNSF. If the evaluating provider in either clinic thought there was sufficient clinical suspicion for FNFS, the project leader recommended the patient be referred for plain radiographs and fast-sequence MRI. As an observational project, there was no requirement for MRI utilization, thus, some IET Soldiers did not receive MRI screening and were subsequently not included in our data analysis. For IET Soldiers seen in the direct access physical therapy clinic, a physical therapist provided all care and collected project data.

\section{Outcomes}

We used a positive finding for FNSF on either the prerequisite plain radiographs or a subsequent fastsequence MRI as determined by the radiologist as the reference standard for this project. We included only data from IET Soldiers who underwent fast-sequence MRI based on provider suspicion of the presence of a FNSF.

Table 1 presents the categories of the 18 variables collected from each subject evaluated. We selected variables based on published association or positive predictive potential for lower extremity stress fractures. Age, gender, and race/ethnicity are potential factors in the development of stress fractures in military recruits and athletes. ${ }^{11,12}$ Alcohol consumption and cigarette smoking negatively influence bone quality, potentially increasing the overall fracture risk of those involved in lower extremity impact activities. ${ }^{17,22}$ Prior exercise history, overall aerobic fitness, and nutritional status also influence the occurrence of stress fractures in the military and athletic populations. ${ }^{10,23,24}$ We used the SCOFF and the Eating disorder Screen for Primary care (ESP) to screen for eating disorders. ${ }^{25-27}$ The SCOFF corresponds to specific words in each of the five questions within this questionnaire (Sick, Control, One, Fat, and Food). The SCOFF and ESP are validated eating disorder screening questionnaires. ${ }^{27}$ The SCOFF has a sensitivity of $78 \%$ and a specificity of $88 \%$ while the ESP has a sensitivity of $100 \%$ and specificity of $71 \%$, each with a cutoff score of two or more abnormal responses. ${ }^{27}$ We also collected data on anthropometric measurements, pain locations, gluteus medius muscle strength, and hip rotation range of motion. ${ }^{10,16,17,28}$ Finally, we included common orthopedic special tests used for assessing lower extremity stress injuries. ${ }^{16,17,29}$

\section{Sample Size}

Given the novel purpose and exploratory nature of this project, we set a goal of 10 personnel per variable with a target of 180 personnel prior to the start of the project. ${ }^{30,31}$ We anticipated no more than six of the 
18 independent variables of interest being clinically feasible to develop a positive predictive rule for FNSF in this population.

\section{Statistical Consideration}

We analyzed all data using IBM SPSS Version 26 (Chicago, Illinois) with a $p$-value of $<0.05$ considered statistically significant. Descriptive statistics were calculated and reported. Pearson and Spearman's correlation coefficients were calculated for all variables to evaluate the strength of any potential relationships with MRI outcomes. We conducted linear regression analysis on variables found to have significant correlations, making note of variables retaining significance within the regression coefficient analysis. We removed variables that did not demonstrate significance in the prediction model prior to subsequent regression analyses. We continued this step-wise process until all non-significant variables were removed from the model. We then generated receiver operating characteristic (ROC) curves on correlated variables to assess individual performance when screening for FNSF with MRI imaging. Due to the high potential for long-term morbidity following a missed fracture ${ }^{15,32}$, we strived to maximize variable sensitivity at $100 \%$, similar to previous literature developing radiography decision rules. ${ }^{30} \mathrm{We}$ used adjusted $\mathrm{R}^{2}$ values to estimate regression model effect size and calculated $95 \%$ confidence for all relevant data.

\section{Results}

We collected data on 265 IET Soldiers seeking care at the two clinics. Eighty-one Soldiers did not undergo MRI screening based on provider decisions and were excluded from the final data analysis. The final data analysis included 184 IET Soldiers (140 females, 44 males) evaluated with MRI. Table 2 displays the frequency analysis separated by gender and MRI outcomes. Figure 1 illustrates self-reported pain locations in IET Soldiers with confirmed FNSF and those without a FNSF. Darker colors within each map signify repeated pain locations.

\section{Frequency Analysis}

We identified 49 FNSFs among the 184 IET Soldiers. Table 2 shows the frequency analysis separated by gender and MRI outcomes. In the current sample, there were more females diagnosed with FNSF $(n=37)$ compared to males $(n=12)$. Within our sample, the odds of incurring a FNSF during IET were 0.35 in females and 0.375 in males. Non-Hispanic white females had the highest occurrence of FNSF; 30 IET personnel accounting for $61.2 \%$ of all positive MRI outcomes. Of all personnel diagnosed with FNSF, $79.6 \%$ were of non-Hispanic ethnicity. Only $8.2 \%$ (15) of IET Soldiers reported using chewing tobacco or smoking prior to the start of training, while $17.4 \%$ (32) reported alcohol consumption prior to training. Outcomes of the eating disorder screening revealed six IET Soldiers (four males, 2 females) with an elevated risk when using the ESP screening criteria. Of these six Soldiers, one male and two females tested positive for FNSF. Three male Soldiers showed an elevated risk for eating disorder when using the SCOFF criteria, but none developed a FNSF. The SCOFF and ESP screening questionnaires identified two 
similar male Soldiers as having an elevated risk for eating disorder, neither of which developed a FNSF. A chi-square test for independence found no significant association between gender and MRI outcomes, $X^{2}(1)=0.012, p=0.912$. The odds for developing a FNSF in females versus males within our project group was 1.044 (95\% Cl 0.487-2.238).

\section{Correlation Analysis}

Initial investigation revealed 10 significant correlations as noted in Table 3 displaying pooled correlations and Table 4 displaying gender-split correlations. To capture all potential predictive variables, we reported both Pearson and Spearman's correlation coefficients as they varied slightly in identifying correlated variables across the pooled and gender-split analyses. All predictor variables were deemed to have a low to moderate strength of correlation to positive MRI outcomes. Only the male gender-split analyses noted a moderate correlation strength with two variables (weight and hop test). All the correlated variables displayed poor ability to discriminate IET Soldiers with and without FNSF based on pooled and gendersplit ROC curve analyses, as noted in Figs. 2, 3, and 4 respectively. The maximum estimated sensitivity for any of the 10 variables was $0.63(95 \% \mathrm{Cl} 0.537-0.722)$ for pooled, $0.62(95 \% \mathrm{Cl} 0.514-0.729)$ for female gender-split, and 0.69 ( $95 \% \mathrm{Cl} 0.510-0.860)$ for male gender-split.

\section{Regression Analysis}

Initial linear regression analysis included all significant variables the correlation analyses. We conducted both pooled and gender-split regression analyses with outcome data reported in Table 5 and Table 6 respectively. The pooled data regression model displayed statistically significant ability to predict MRI outcomes, $F(10,1172)=4.617, p<0.005$; however, the predictor variables only accounted for $16.6 \%$ (adjusted $\mathrm{R}^{2}$ value) of the variability of MRI outcomes. Adjusted $\mathrm{R}^{2}$ also signifies a small effect size for this pooled prediction model. Five variables showed significance within this model as noted in Table 5. Regression analysis of the female gender-split model also showed a statistically significant ability to predict MRI outcomes, $F(10,128)=5.248, p<0.005$, with the predictor variables accounting for $23.5 \%$ of MRI outcome variability. This model also displayed a small effect size, based on the adjusted $R^{2}$ value. The male gender-split regression model was non-significant. Subsequent regression models only utilizing significant variables from previous models did not improve prediction abilities or effect sizes as noted from adjusted $R^{2}$ values.

\section{Discussion}

This was the first attempt to identify clinical findings predictive of femoral neck stress fractures in IET personnel. We identified 10 variables with weak correlation to positive MRI outcomes for FNSF, with no apparent combination of variables demonstrating clinical utility. Although we identified significant interactions within a regression model, it had limited predictor variable ability to account for MRI outcome variance. Based on these findings, we are unable to recommend making advanced imaging decisions solely on the post-test results of our tested variables due to the lack of estimated variable sensitivity. With a false negative rate of up to $38 \%$, we lack confidence in these results and therefore cannot recommend 
any changes to the current FNSF screening methods. We recommend that clinicians retain an extremely low threshold for ordering advanced imaging in this population with the gold standard remaining MRI.

Our results are consistent with previous studies that identify the female gender as the most consistent predictor of FNSF, although FNSF were identified in both genders. However, the identification of more stress fractures in females may be secondary to a greater proportion of females tested than males. Future efforts to develop a sensitive predictive model may need to focus on additional gender specific factors to develop a clinically feasible prediction model. In the military training environment, factors related to the female athlete are of interest. Similar to previous reports, ${ }^{12}$ we observed a higher incidence of FNSF in races other than black at $93.9 \%$. Only eight participants (six females, two males) used tobacco products prior to the start of basic training and later developed a FNSF. This occurrence may be underrepresented as we did not question or specify about e-cigarette or vaping use. Prior studies have also linked eating disorders or hypocaloric states to the occurrence of stress fractures; however, these studies used subjects previously diagnosed with an eating order. ${ }^{10,23,33}$ To our understanding, no studies have explored possible relationships between individual eating disorder screening questions and positive diagnosis of FNSF. With only $6 \%$ of personnel displaying findings suggesting the presence of an eating disorder while also developing a FNSF, we are unable to determine a link between the two.

We corroborated past summative observations that FNSF is a multifactorial disorder posing a challenge to diagnosis with patient-reported history or physical examination methods alone. This diagnostic complexity is depicted through the pain maps of IET Soldiers with and without FNSF, Fig. 1. Patientreported pain maps can be a vital part of the clinical reasoning and diagnostic process as noted from previous studies. ${ }^{34-37}$ While there is high variability in individual clinical presentations, better understanding of pain location as it relates to FNSF may improve initial screening. While they do not hold certainty in a diagnosis, they can provide insight into pain origin, potential referral sources, changes in symptoms over time, and overall dispersion of symptoms. The pain referral maps collected in this project illustrate similarity between IET Soldiers with and without FNSF. Those with and without a fracture reported both anterior and posterior pain commonly and a few reported referral patterns distally into the thigh and knee regions. One difference noted in these maps that may help future investigations is the lack of central low back and sacroiliac region pain in IET personnel with confirmed FNSF. Previous studies have described the positive impact pain referral maps can have on the differential diagnosis process for multiple regions of the body. ${ }^{34,38,39}$ This project may indicate FNSF pain does not produce low back pain referral patterns as noted in other literature. ${ }^{38}$ To our knowledge, this is the first project documenting self-reported pain maps in IET personnel with FNSF.

\section{Limitations:}

A limitation of our project was the small sample size. Although we reached our targeted sample size of 180 personnel undergoing MRI evaluation, the small noted effect sizes could infer that our sample size was not adequate. Our sample also was predominately female, questioning the outcome of females being at a great risk. Additionally, 81 individuals did not complete MRI evaluation limiting the total 
number of IET personnel analyzed. This was due to the observational nature of this project and no mandate for providers to screen with MRI. Another limitation may be that our project consisted of individuals undergoing advanced individual training (AIT), which is the second part of their initial military training following basic combat training (BCT). During $B C T$, there is a high attrition rate secondary to musculoskeletal injuries that typically occurs early in the training process. ${ }^{1}$ Military IET personnel completing AIT may be a population that is less susceptible to FNSF than those participating in BCT. Regarding tobacco product utilization, we only assessed standard tobacco use and not alternative tobacco products. Vaping may pose an underlying stress fracture risk, but we are unaware of any project assessing this risk to date. Overall, our sample reporting tobacco and alcohol use is smaller than previous studies. ${ }^{40}$ The prevalence of eating disorders within the military population is understudied to make a comparison. ${ }^{41}$ None of the screening within this project assessed consumption of soda, energy drinks, or other consumable stimulants.

\section{Conclusions}

While we identified multiple variables with the potential to guide clinical decision-making processes regarding the use of MRI for FNSF screening, the clinical importance of these findings appears limited. Failing to identify a FNSF in IET personnel can result in substantial health complications for the patient, added costs to the military health care system, and a decrease in military unit readiness. We recommend clinicians have a low threshold when deciding whether to screen IET personnel with MRI that are suspected of having a FNSF. Specifically, when screening personnel in AIT with hip and/or groin pain with a clinical suspicion of FNSF, it may be best to immediately screen with fast-sequence MRI due to the multifactorial nature of the disorder and the likelihood the subject will undergo multiple evaluations with either a primary care physician or physical therapist prior to diagnostic confirmation. This delay can result in additional healthcare costs, possible fracture progression and displacement, and lost training time.

\section{Declarations}

\section{Ethics Approval and Consent to Participate}

This study was deemed as a process improvement project by the Brooke Army Medical Center Institutional Review Board on 7 August 2017.

\section{Consent for Publication}

Not applicable.

\section{Availability of Data and Materials}

The datasets generated and/or analyzed during the this project are not publicly available due the project being deemed a process improvement project, but are available from the corresponding author on 
reasonable request.

\section{Competing Interests}

The authors declare that they have no competing interests.

\section{Funding}

No funding was received for this project.

\section{Author's Contributions}

JZ - Author was responsible for project design, data collection, data analysis, data interpretation, and manuscript development.

GD - Author assisted in the project design, data interpretation, and manuscript development.

$\mathrm{ML}$ - Author assisted in the project design, data analysis, data interpretation, and manuscript development.

$\mathrm{JM}$ - Author assisted in the project design, data interpretation, and manuscript development.

CA - Author was responsible for project design, data collection, data interpretation, and manuscript development.

\section{Acknowledgements}

We thank all the BAMC physical therapy staff that assisted during data collection. Your diligent efforts helped make this project possible.

\section{Author's Information}

JZ - Department of Physical Therapy, Carl R. Darnall Army Medical Center, Ft. Hood, TX, 76544; ArmyBaylor Doctoral Fellowship in Orthopaedic Manual Physical Therapy, Brooke Army Medical Center, 1179 Garden Ave, Fort Sam Houston TX, 78234

GD - Army-Baylor Doctoral Fellowship in Orthopaedic Manual Physical Therapy, Brooke Army Medical Center, 1179 Garden Ave, Fort Sam Houston TX, 78234

ML - Army-Baylor Doctoral Program in Physical Therapy, 3630 Stanley Road, Fort Sam Houston TX, 78234; Department of Physical Therapy, Texas State University, Round Rock, TX 78665

JM - Army-Baylor Doctoral Program in Physical Therapy, 3630 Stanley Road, Fort Sam Houston TX, 78234

CA - University of Cincinnati, College of Allied Health Sciences. P.O. Box 670394 Cincinnati, OH, 45267 


\section{References}

1. Chalupa RL, Aberle C, Johnson AE. Observed Rates of Lower Extremity Stress Fractures After Implementation of the Army Physical Readiness Training Program at JBSA Fort Sam Houston. US Army Medical Department journal. 2016:6-9.

2. Lee D. Stress fractures, active component, U.S. Armed Forces, 2004-2010. Msmr. 2011;18(5):8-11.

3. Scott SJ, Feltwell DN, Knapik JJ, et al. A multiple intervention strategy for reducing femoral neck stress injuries and other serious overuse injuries in U.S. Army Basic Combat Training. Military medicine. 2012;177(9):1081-1089.

4. Kupferer KR, Bush DM, Cornell JE, et al. Femoral neck stress fracture in Air Force basic trainees. Military medicine. 2014;179(1):56-61.

5. Chalupa RL, Rivera JC, Tennent DJ, Johnson AE. Correlation Between Femoral Neck Shaft Angle and Surgical Management in Trainees With Femoral Neck Stress Fractures. US Army Medical Department journal. 2016:1-5.

6. Khurana B, Okanobo H, Ossiani M, Ledbetter S, Al Dulaimy K, Sodickson A. Abbreviated MRI for patients presenting to the emergency department with hip pain. AJR American journal of roentgenology. 2012;198(6):W581-588.

7. May LA, Chen DC, Bui-Mansfield LT, O'Brien SD. Rapid Magnetic Resonance Imaging Evaluation of Femoral Neck Stress Fractures in a U.S. Active Duty Military Population. Military medicine. 2017;182(1):e1619-e1625.

8. Pihlajamaki HK, Ruohola JP, Kiuru MJ, Visuri TI. Displaced femoral neck fatigue fractures in military recruits. The Journal of bone and joint surgery American volume. 2006;88(9):1989-1997.

9. Friedl KE, Evans RK, Moran DS. Stress fracture and military medical readiness: bridging basic and applied research. Medicine and science in sports and exercise. 2008;40(11 Suppl):S609-622.

10. Jacobs JM, Cameron KL, Bojescul JA. Lower extremity stress fractures in the military. Clinics in sports medicine. 2014;33(4):591-613.

11. Knapik J, Montain SJ, McGraw S, Grier T, Ely M, Jones BH. Stress fracture risk factors in basic combat training. International journal of sports medicine. 2012;33(11):940-946.

12. Waterman BR, Gun B, Bader JO, Orr JD, Belmont PJ. Epidemiology of Lower Extremity Stress Fractures in the United States Military. Military medicine. 2016;181(10):1308-1313.

13. Moo IH, Lee YH, Lim KK, Mehta KV. Bilateral femoral neck stress fractures in military recruits with unilateral hip pain. Journal of the Royal Army Medical Corps. 2016;162(5):387-390.

14. Polacek M, Smabrekke A. Displaced stress fracture of the femoral neck in young active adults. BMJ case reports. 2010;2010.

15. Robertson GA, Wood AM. Femoral Neck Stress Fractures in Sport: A Current Concepts Review. Sports Med Int Open. 2017;1(2):E58-e68.

16. Green N, Mathews J. The management of acute hip pain in the military: femoral neck stress fractures and tears of the acetabular labrum. Journal of the Royal Naval Medical Service. 2016;102(2):124- 
129.

17. Knapik JJ, Reynolds K, Hoedebecke KL. Stress Fractures: Etiology, Epidemiology, Diagnosis, Treatment, and Prevention. Journal of special operations medicine : a peer reviewed journal for SOF medical professionals. 2017;17(2):120-130.

18. Niva MH, Mattila VM, Kiuru MJ, Pihlajamaki HK. Bone stress injuries are common in female military trainees: a preliminary study. Clinical orthopaedics and related research. 2009;467(11):2962-2969.

19. Wright AA, Hegedus EJ, Lenchik L, Kuhn KJ, Santiago L, Smoliga JM. Diagnostic Accuracy of Various Imaging Modalities for Suspected Lower Extremity Stress Fractures: A Systematic Review With Evidence-Based Recommendations for Clinical Practice. The American journal of sports medicine. 2016;44(1):255-263.

20. National Guideline C. ACR Appropriateness Criteria\&reg; stress (fatigue/insufficiency) fracture, including sacrum, excluding other vertebrae. 2016.

21. Iwata T, Nozawa S, Dohjima T, et al. The value of T1-weighted coronal MRI scans in diagnosing occult fracture of the hip. J Bone Joint Surg Br. 2012;94(7):969-973.

22. Johnson TL, Gaddini G, Branscum AJ, et al. Effects of chronic heavy alcohol consumption and endurance exercise on cancellous and cortical bone microarchitecture in adult male rats. Alcoholism, clinical and experimental research. 2014;38(5):1365-1372.

23. Robinson L, Aldridge V, Clark EM, Misra M, Micali N. A systematic review and meta-analysis of the association between eating disorders and bone density. Osteoporosis international : a journal established as result of cooperation between the European Foundation for Osteoporosis and the National Osteoporosis Foundation of the USA. 2016;27(6):1953-1966.

24. Sanchez-Santos MT, Davey T, Leyland KM, et al. Development of a Prediction Model for Stress Fracture During an Intensive Physical Training Program: The Royal Marines Commandos. Orthopaedic journal of sports medicine. 2017;5(7):2325967117716381.

25. Lahteenmaki S, Aalto-Setala T, Suokas JT, et al. Validation of the Finnish version of the SCOFF questionnaire among young adults aged 20 to 35 years. BMC psychiatry. 2009;9:5.

26. Hill LS, Reid F, Morgan JF, Lacey JH. SCOFF, the development of an eating disorder screening questionnaire. The International journal of eating disorders. 2010;43(4):344-351.

27. Cotton MA, Ball C, Robinson P. Four simple questions can help screen for eating disorders. Journal of general internal medicine. 2003;18(1):53-56.

28. Warden SJ, Davis IS, Fredericson M. Management and prevention of bone stress injuries in longdistance runners. J Orthop Sports Phys Ther. 2014;44(10):749-765.

29. Behrens SB, Deren ME, Matson A, Fadale PD, Monchik KO. Stress fractures of the pelvis and legs in athletes: a review. Sports health. 2013;5(2):165-174.

30. Walenkamp MM, Bentohami A, Slaar A, et al. The Amsterdam wrist rules: the multicenter prospective derivation and external validation of a clinical decision rule for the use of radiography in acute wrist trauma. BMC Musculoskelet Disord. 2015;16:389. 
31. Han K, Song K, Choi BW. How to Develop, Validate, and Compare Clinical Prediction Models Involving Radiological Parameters: Study Design and Statistical Methods. Korean journal of radiology. 2016;17(3):339-350.

32. Lee $\mathrm{CH}$, Huang GS, Chao KH, Jean JL, Wu SS. Surgical treatment of displaced stress fractures of the femoral neck in military recruits: a report of 42 cases. Archives of orthopaedic and trauma surgery. 2003;123(10):527-533.

33. Tenforde AS, Carlson JL, Chang A, et al. Association of the Female Athlete Triad Risk Assessment Stratification to the Development of Bone Stress Injuries in Collegiate Athletes. The American journal of sports medicine. 2017;45(2):302-310.

34. Bayam L, Ahmad MA, Naqui SZ, Chouhan A, Funk L. Pain mapping for common shoulder disorders. American journal of orthopedics (Belle Mead, NJ). 2011;40(7):353-358.

35. Kurosawa D, Murakami E, Aizawa T. Referred pain location depends on the affected section of the sacroiliac joint. European spine journal : official publication of the European Spine Society, the European Spinal Deformity Society, and the European Section of the Cervical Spine Research Society. 2015;24(3):521-527.

36. Louw A, Puentedura EL, Mintken P. Use of an abbreviated neuroscience education approach in the treatment of chronic low back pain: a case report. Physiotherapy theory and practice. 2012;28(1):5062.

37. Louw A, Zimney K, Puentedura EJ, Diener I. The efficacy of pain neuroscience education on musculoskeletal pain: A systematic review of the literature. Physiotherapy theory and practice. 2016;32(5):332-355.

38. Lesher JM, Dreyfuss P, Hager N, Kaplan M, Furman M. Hip joint pain referral patterns: a descriptive study. Pain medicine (Malden, Mass). 2008;9(1):22-25.

39. Fortin JD, Aprill CN, Ponthieux B, Pier J. Sacroiliac joint: pain referral maps upon applying a new injection/arthrography technique. Part II: Clinical evaluation. Spine. 1994;19(13):1483-1489.

40. Cosman F, Ruffing J, Zion M, et al. Determinants of stress fracture risk in United States Military Academy cadets. Bone. 2013;55(2):359-366.

41. Bartlett BA, Mitchell KS. Eating disorders in military and veteran men and women: A systematic review. The International journal of eating disorders. 2015;48(8):1057-1069.

42. Astur DC, Zanatta F, Arliani GG, Moraes ER, Pochini Ade C, Ejnisman B. Stress fractures: definition, diagnosis and treatment. Revista brasileira de ortopedia. 2016;51(1):3-10.

43. Jones BH, Thacker SB, Gilchrist J, Kimsey CD, Jr., Sosin DM. Prevention of lower extremity stress fractures in athletes and soldiers: a systematic review. Epidemiologic reviews. 2002;24(2):228-247.

44. Sloan A, Hussain I, Maqsood M, Eremin O, El-Sheemy M. The effects of smoking on fracture healing. The surgeon : journal of the Royal Colleges of Surgeons of Edinburgh and Ireland. 2010;8(2):111116.

45. Ackerman KE, Pierce L, Guereca G, et al. Hip structural analysis in adolescent and young adult oligoamenorrheic and eumenorrheic athletes and nonathletes. The Journal of clinical endocrinology 
and metabolism. 2013;98(4):1742-1749.

46. Moran DS, Finestone AS, Arbel Y, Shabshin N, Laor A. A simplified model to predict stress fracture in young elite combat recruits. Journal of strength and conditioning research. 2012;26(9):2585-2592.

47. Biz C, Berizzi A, Crimi A, Marcato C, Trovarelli G, Ruggieri P. Management and treatment of femoral neck stress fractures in recreational runners: a report of four cases and review of the literature. Acta bio-medica : Atenei Parmensis. 2017;88(4 -s):96-106.

48. Johansson $\mathrm{H}$, Kanis JA, Oden A, et al. A meta-analysis of the association of fracture risk and body mass index in women. Journal of bone and mineral research : the official journal of the American Society for Bone and Mineral Research. 2014;29(1):223-233.

49. Webber BJ, Trueblood WE, Tchandja JN, Federinko SP, Cropper TL. Concurrent bilateral femoral neck stress fractures in a military recruit: a case report. Military medicine. 2015;180(1):e134-137.

50. Duquette TL, Watson DJ. Femoral neck stress fracture in a military trainee. J Orthop Sports Phys Ther. 2010;40(12):834.

51. Cleland J, Koppenhaver S, Su J. Netter's Orthopaedic Clinical Examination: An Evidence-Based Approach, 2e (Netter Clinical Science). Saunders; 2010.

\section{Tables}

\section{Table 1}

Proposed Risk Factors or Diagnostic Tests Associated with Femoral Neck Stress Fractures 


\begin{tabular}{|c|c|}
\hline Variable & Reference \\
\hline Age & $2,7,11,12,42$ \\
\hline Gender & $2,4,10-12,42$ \\
\hline Race/Ethnicity & $2,10-12,42$ \\
\hline History of Alcohol Use & 22,42 \\
\hline History of Smoking Use & $2,8,17,43,44$ \\
\hline Nutritional History & $10,23,24,33,45$ \\
\hline Exercise History & $10,24,46$ \\
\hline Aerobic Fitness & $4,10,17,46$ \\
\hline Amenorrhea History & $14,29,33,45,47$ \\
\hline Birth Control Use & 10 \\
\hline Previous Stress Fracture History & No Studies \\
\hline Duration of Pain & No Studies \\
\hline $\mathrm{BMI}$ & $2,10,48$ \\
\hline Tenderness to Palpation & $16,17,49,50$ \\
\hline Gluteus Medius Muscle Strength & 7,28 \\
\hline Hip/Thigh Circumferential Measurements & $5,16,17,46$ \\
\hline Hip Rotation Range of Motion & 10,28 \\
\hline Special Tests: & $16,17,28,29,51$ \\
\hline \multicolumn{2}{|l|}{ FABER } \\
\hline \multicolumn{2}{|l|}{ Patellar-Pubic Percussion } \\
\hline \multicolumn{2}{|l|}{ Hop Test } \\
\hline Heel Strike & \\
\hline
\end{tabular}

\section{Table 2}


With Femoral Neck

Stress Fracture

$\mathrm{N}=49$

\section{Gender}

Female

Male

Total

\section{Age (yrs)}

Female

Male

Total

Race

White

Black

Black/White

Black/Native Hawaiian/Pacific Islander

Asian

Asian/White

American Indian/Alaska Native

American

Indian/Alaska/Native/White

Native Hawaiian/Pacific

Islander

Other

Black (all inclusive)

Non-Black (all inclusive)

\section{Ethnicity}

Hispanic

Non-Hispanic
37 (75.5\%)

$12(24.5 \%)$

49 (26.6\%)

$22.14 \pm 3.94(18-$

31)

$21.42 \pm 2.02(18-$

24)

$21.96 \pm 3.56(18-$

31)

37 (75.5\%)

$3(6.1 \%)$

$0(0.0 \%)$

$0(0.0 \%)$

$3(6.1 \%)$

$0(0.0 \%)$

$2(4.1 \%)$

$2(4.1 \%)$

$1(2.0 \%)$

$1(2.0 \%)$

$3(6.1 \%)$

46 (93.9\%)
Without Femoral Neck

Stress Fracture

$\mathrm{N}=135$
Pooled Totals

$\mathrm{N}=184$

$140(76.1 \%)$

$44(23.9 \%)$

$184(100 \%)$
103 (76.3\%)

$32(23.7 \%)$

135 (73.4\%)

$20.71 \pm 3.27(18-33)$

$20.50 \pm 3.53(18-35)$

$20.66 \pm 3.32(18-35)$

$20.75 \pm 3.19$ (18-

35)

$21.01 \pm 3.43(18-$ 35)

$132(71.7 \%)$

$24(13.0 \%)$

$2(1.1 \%)$

$1(0.5 \%)$

$7(3.8 \%)$

$2(1.1 \%)$

$3(1.6 \%)$

$2(1.1 \%)$

$1(0.5 \%)$

$10(5.4 \%)$

$27(14.7 \%)$

$157(85.3 \%)$

$111(82.2 \%)$

$41(22.3 \%)$

$10(20.4 \%) \quad 31(23.0 \%)$

$143(77.7 \%)$ 
Tobacco Use Prior to BCT

\begin{tabular}{|c|c|c|c|}
\hline Yes & $8(16.3 \%)$ & $7(5.2 \%)$ & $15(8.2 \%)$ \\
\hline No & $41(83.7 \%)$ & $128(94.8 \%)$ & $169(91.8 \%)$ \\
\hline \multicolumn{4}{|c|}{ Alcohol Use Prior to BCT } \\
\hline Yes & $12(24.5 \%)$ & $20(14.8 \%)$ & $32(17.4 \%)$ \\
\hline No & 37 (75.5\%) & $115(85.2 \%)$ & $152(82.6 \%)$ \\
\hline \multicolumn{4}{|c|}{ Height (cm) } \\
\hline Female & $\begin{array}{l}162.75 \pm 5.66 \\
(149.86-177.80)\end{array}$ & $\begin{array}{l}162.63 \pm 7.60(132.08- \\
192.02)\end{array}$ & $\begin{array}{l}162.66 \pm 7.12 \\
(132.08-192.02)\end{array}$ \\
\hline \multirow[t]{2}{*}{ Male } & $\begin{array}{l}171.49 \pm 12.44 \\
(142.0-185.42)\end{array}$ & $\begin{array}{l}178.32 \pm 9.27 \\
(160.02-198.12)\end{array}$ & $\begin{array}{l}176.46 \pm 10.53 \\
(142.0-198.12)\end{array}$ \\
\hline & $\begin{array}{l}164.89 \pm 8.59 \\
(142.00-185.42)\end{array}$ & $\begin{array}{l}166.38 \pm 10.44 \\
(132.08-198.12)\end{array}$ & $\begin{array}{l}165.98 \pm 9.98 \\
(132.08-198.12)\end{array}$ \\
\hline
\end{tabular}

\section{Weight (kg)}

Female

$63.24 \pm 8.49(50.35-$

$99.80)$

$61.97 \pm 7.60(47.6-$

78.93)

$62.31 \pm 7.84$

(47.60-99.80)

Male

$\begin{array}{ll}69.74 \pm 6.68(56.70- & 76.82 \pm 8.98(64.5- \\ 78.9) & 95.70)\end{array}$

$74.89 \pm 8.93$

(56.70-95.70)

Total

$64.83 \pm 8.50(50.35-$

$99.80)$

$65.52 \pm 10.15(47.60-$

95.70)

$65.33 \pm 9.72$

$(47.6-99.8)$

\section{BMI}

Female

$23.84 \pm 2.57(19.66-$ $34.46)$

$23.46 \pm 2.74(18.16-$ 32.5)

$23.56 \pm 2.69$

(18.16-34.46)

Male

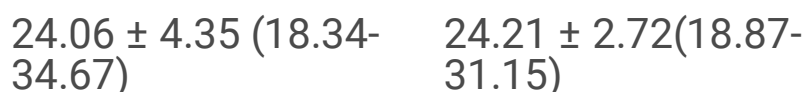

$24.17 \pm 3.19$

(18.34-34.67)

Total

$24.06 \pm 4.35(18.34-$ 34.67 )

\section{Duration of Pain (weeks)}

Female

Male
$6.91 \pm 8.12(1.0-$ 40.0)
$24.21 \pm 2.72(18.87-$

$31.15)$

$23.71 \pm 2.82$

(18.16-34.67)
$7.78 \pm 11.20(0.5-$ 88.0)
$7.55 \pm 10.45(0.5-$ 88.0) 
Total

$5.83 \pm 5.22(1.0-$

16.0)

$4.36 \pm 4.18(1.0-20.0)$

$4.77 \pm 4.48(1.0-$

$6.99 \pm 10.10(0.5-$

$6.65 \pm 7.47(1.0-$ 40.0) 88.0) 88.0)

\section{Pain Rating (Numeric Pain \\ Rating Scale score [0-10])}

Female

Male

$3.86 \pm 2.12(0-7)$

$4.62 \pm 1.86(0-8)$

$4.42 \pm 1.96(0-8)$

Total

$5.50 \pm 2.36(3-10) \quad 4.47 \pm 2.40(0-8)$

$4.27 \pm 2.27(0-10)$

$4.59 \pm 1.99(0-8)$

$4.75 \pm 2.40$

$4.50 \pm 2.07(0-10)$

Total Participants

49

135

184

*Values are presented as N (percentage), mean +/- SD (range).

Table 3

Pooled Correlation Analysis

\begin{tabular}{|lll|}
\hline Variable & $\begin{array}{l}\text { Pearson's Correlation } \\
\text { Coefficient }\end{array}$ & $\begin{array}{l}\text { Spearman's } \\
\text { rho }\end{array}$ \\
\hline Age & $0.168, P=0.022$ & $\begin{array}{l}0.196, P= \\
0.008\end{array}$ \\
\hline Race (Nonblack VS Black) & $-0.146, P=0.049$ & $\begin{array}{l}-0.146, P= \\
0.049\end{array}$ \\
\hline Prior Tobacco Use & $0.180, P=0.014$ & $0.180, P=$ \\
& & 0.014 \\
Anterior Groin Palpation Tenderness & $-0.145, P=0.049$ & $-0.145, P=$ \\
& & 0.049 \\
\hline Patellar Percussion Test & $0.157, P=0.033$ & $0.157, P=$ \\
Hop Test & & 0.033 \\
\hline Are You Satisfied with Your Eating Patterns (ESP & $0.220, P=0.003$ & $0.221, P=$ \\
screening questionnaire) & $0.188, P=0.010$ & 0.003 \\
\hline
\end{tabular}

Table 4 
Gender-Split Correlation Analysis

\begin{tabular}{|c|c|c|c|}
\hline Gender & Variable & $\begin{array}{l}\text { Pearson's Correlation } \\
\text { Coefficient }\end{array}$ & $\begin{array}{l}\text { Spearman's } \\
\text { rho }\end{array}$ \\
\hline \multirow[t]{7}{*}{ Female } & Age & $0.180, P=0.033$ & $\begin{array}{l}0.175, P= \\
0.038\end{array}$ \\
\hline & Current Pain Level & $-0.171, P=0.043$ & N/A \\
\hline & Prior Tobacco Use & $0.271, P=0.001$ & $\begin{array}{l}0.271, P= \\
0.001\end{array}$ \\
\hline & Patellar Percussion Test & $0.174, P=0.040$ & $\begin{array}{l}0.174, P= \\
0.040\end{array}$ \\
\hline & Hop Test & $0.199, P=0.018$ & $\begin{array}{l}0.203, P= \\
0.016\end{array}$ \\
\hline & $\begin{array}{l}\text { Does Food Dominate Your Life (SCOFF screening } \\
\text { questionnaire) }\end{array}$ & $0.201, P=0.017$ & $\begin{array}{l}0.221, P= \\
0.014\end{array}$ \\
\hline & $\begin{array}{l}\text { Are you Satisfied with Your Eating Patterns (ESP } \\
\text { screening questionnaire) }\end{array}$ & $0.186, P=0.028$ & $\begin{array}{l}0.186, P= \\
0.028\end{array}$ \\
\hline \multirow[t]{2}{*}{ Male } & Weight (kg) & $-0.375, P=0.017$ & $\begin{array}{l}-0.334, P= \\
0.027\end{array}$ \\
\hline & Hop Test & $0.350, P=0.020$ & $\begin{array}{l}0.333, P= \\
0.027\end{array}$ \\
\hline
\end{tabular}

\section{Table 5}

Pooled Sample Logistic Regression Analysis 


\begin{tabular}{|c|c|c|c|}
\hline$R^{2}=0.212$ & Predictor Variable & $\begin{array}{l}P \\
\text { Value }\end{array}$ & $95 \% \mathrm{Cl}$ \\
\hline $\begin{array}{l}\text { Adjusted } \mathrm{R}^{2}= \\
0.166\end{array}$ & Age & $0.044^{*}$ & $\begin{array}{l}0.001- \\
0.036\end{array}$ \\
\hline $\begin{array}{l}\text { Effect Size = } \\
16.6 \%\end{array}$ & Race (Black VS Nonblack) & 0.230 & $\begin{array}{l}-0.277- \\
0.067\end{array}$ \\
\hline \multirow[t]{8}{*}{$\begin{array}{l}\text { Model } P \text {-Value }< \\
0.005\end{array}$} & Prior Tobacco Use & $0.046^{\star}$ & $\begin{array}{l}0.005- \\
0.445\end{array}$ \\
\hline & Anterior Groin Palpation Tenderness & $0.002^{\star}$ & $\begin{array}{c}-0.335- \\
(-0.078)\end{array}$ \\
\hline & Hop Test & $0.00 *$ & $\begin{array}{l}0.084- \\
0.288\end{array}$ \\
\hline & Patellar Percussion Test & 0.092 & $\begin{array}{l}-0.027- \\
0.355\end{array}$ \\
\hline & Does Food Dominate Your Life (SCOFF Questionnaire) & 0.819 & $\begin{array}{l}-0.399- \\
0.316\end{array}$ \\
\hline & $\begin{array}{l}\text { Are you Satisfied with Your Eating Patterns (ESP } \\
\text { screening questionnaire) }\end{array}$ & $0.36^{\star}$ & $\begin{array}{l}0.012- \\
0.332\end{array}$ \\
\hline & Weight (kg) & 0.837 & $\begin{array}{l}-0.007- \\
0.006\end{array}$ \\
\hline & Current Pain Level & 0.168 & $\begin{array}{l}-0.053- \\
0.009\end{array}$ \\
\hline
\end{tabular}

*Statistically significant: $P<0.05$

\section{Table 6}

Gender-Split Logistic Regression Analysis 


\begin{tabular}{|c|c|c|c|}
\hline Females & Predictor Variable & $\begin{array}{l}P \\
\text { Value }\end{array}$ & $95 \% \mathrm{Cl}$ \\
\hline & Age & 0.285 & $\begin{array}{l}-0.009- \\
0.031\end{array}$ \\
\hline $\mathrm{R}^{2}=0.291$ & Race (Black VS Nonblack) & 0.205 & $\begin{array}{l}-0.286- \\
0.062\end{array}$ \\
\hline $\begin{array}{l}\text { Adjusted } \mathrm{R}^{2}= \\
0.235\end{array}$ & Prior Tobacco Use & $0.005^{\star}$ & $\begin{array}{l}0.124- \\
0.702\end{array}$ \\
\hline $\begin{array}{l}\text { Effect Size = } \\
23.5 \%\end{array}$ & Anterior Groin Palpation Tenderness & $0.015^{\star}$ & $\begin{array}{l}-0.323- \\
(-0.035)\end{array}$ \\
\hline \multirow[t]{6}{*}{$\begin{array}{l}\text { Model } P \text {-Value }< \\
0.005\end{array}$} & Hop Test & $0.004^{\star}$ & $\begin{array}{l}0.053- \\
0.267\end{array}$ \\
\hline & Patellar Percussion Test & $0.048^{*}$ & $\begin{array}{l}0.002- \\
0.422\end{array}$ \\
\hline & Does Food Dominate Your Life (SCOFF Questionnaire) & $0.038^{*}$ & $\begin{array}{l}0.032- \\
1.174\end{array}$ \\
\hline & $\begin{array}{l}\text { Are you Satisfied with Your Eating Patterns (ESP } \\
\text { screening questionnaire) }\end{array}$ & 0.229 & $\begin{array}{l}-0.072- \\
0.297\end{array}$ \\
\hline & Weight (kg) & 0.093 & $\begin{array}{l}-0.001- \\
0.016\end{array}$ \\
\hline & Current Pain Level & $0.040^{\star}$ & $\begin{array}{l}-0.076- \\
(-0.002)\end{array}$ \\
\hline \multirow[t]{2}{*}{ Males } & Predictor Variable & $\begin{array}{l}P \\
\text { Value }\end{array}$ & $95 \% \mathrm{Cl}$ \\
\hline & Age & 0.839 & $\begin{array}{l}-0.736- \\
2.665\end{array}$ \\
\hline$R^{2}=0.365$ & Race (Black VS Nonblack) & 0.260 & $\begin{array}{l}-1.380- \\
0.386\end{array}$ \\
\hline $\begin{array}{l}\text { Adjusted } \mathrm{R}^{2}= \\
0.173\end{array}$ & Prior Tobacco Use & 0.958 & $\begin{array}{l}-0.339- \\
0.357\end{array}$ \\
\hline $\begin{array}{l}\text { Effect Size = } \\
17.3 \%\end{array}$ & Anterior Groin Palpation Tenderness & 0.070 & $\begin{array}{l}-0.589- \\
0.024\end{array}$ \\
\hline \multirow[t]{2}{*}{$\begin{array}{l}\text { Model } P \text {-Value }= \\
0.081\end{array}$} & Hop Test & $0.043^{*}$ & $\begin{array}{l}0.010- \\
0.606\end{array}$ \\
\hline & Patellar Percussion Test & 0.874 & $\begin{array}{l}-0.464- \\
0.396\end{array}$ \\
\hline
\end{tabular}




\begin{tabular}{|lcc|}
\hline Does Food Dominate Your Life (SCOFF Questionnaire) & 0.365 & $\begin{array}{c}-0.801- \\
0.303\end{array}$ \\
\hline Are you Satisfied with Your Eating Patterns (ESP & $0.046^{*}$ & $\begin{array}{l}0.007- \\
0.670\end{array}$ \\
\hline screening questionnaire) & 0.120 & $\begin{array}{c}-0.030- \\
0.004\end{array}$ \\
\hline Weight (kg) & & 0.074 \\
& & $-0.056-$ \\
\hline Current Pain Level & 0.065 \\
\hline
\end{tabular}

*Statistically significant: $P<0.05$

Figures

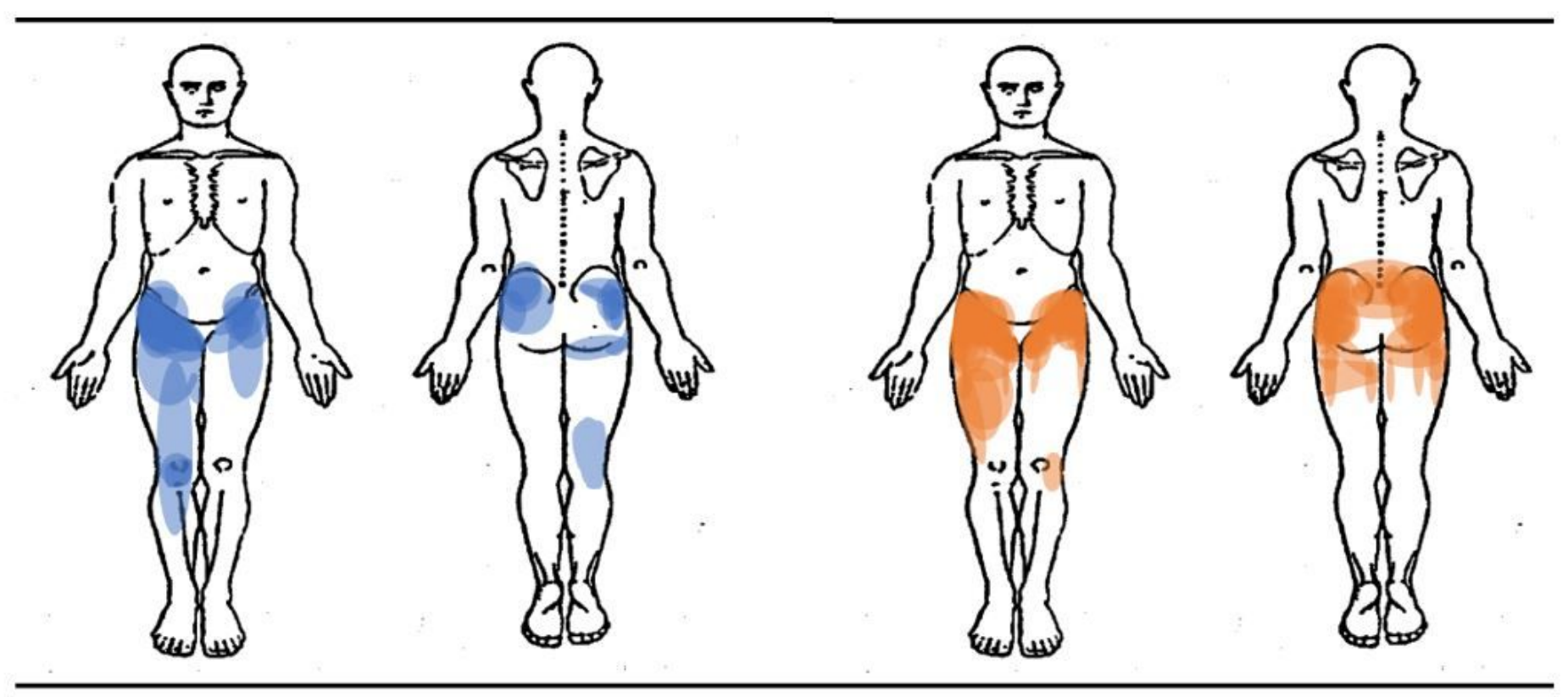

Positive MRI Findings for FNSF

Negative MRI Findings for FNSF

Figure 1

Composite Subject-Reported Pain Distribution Maps 


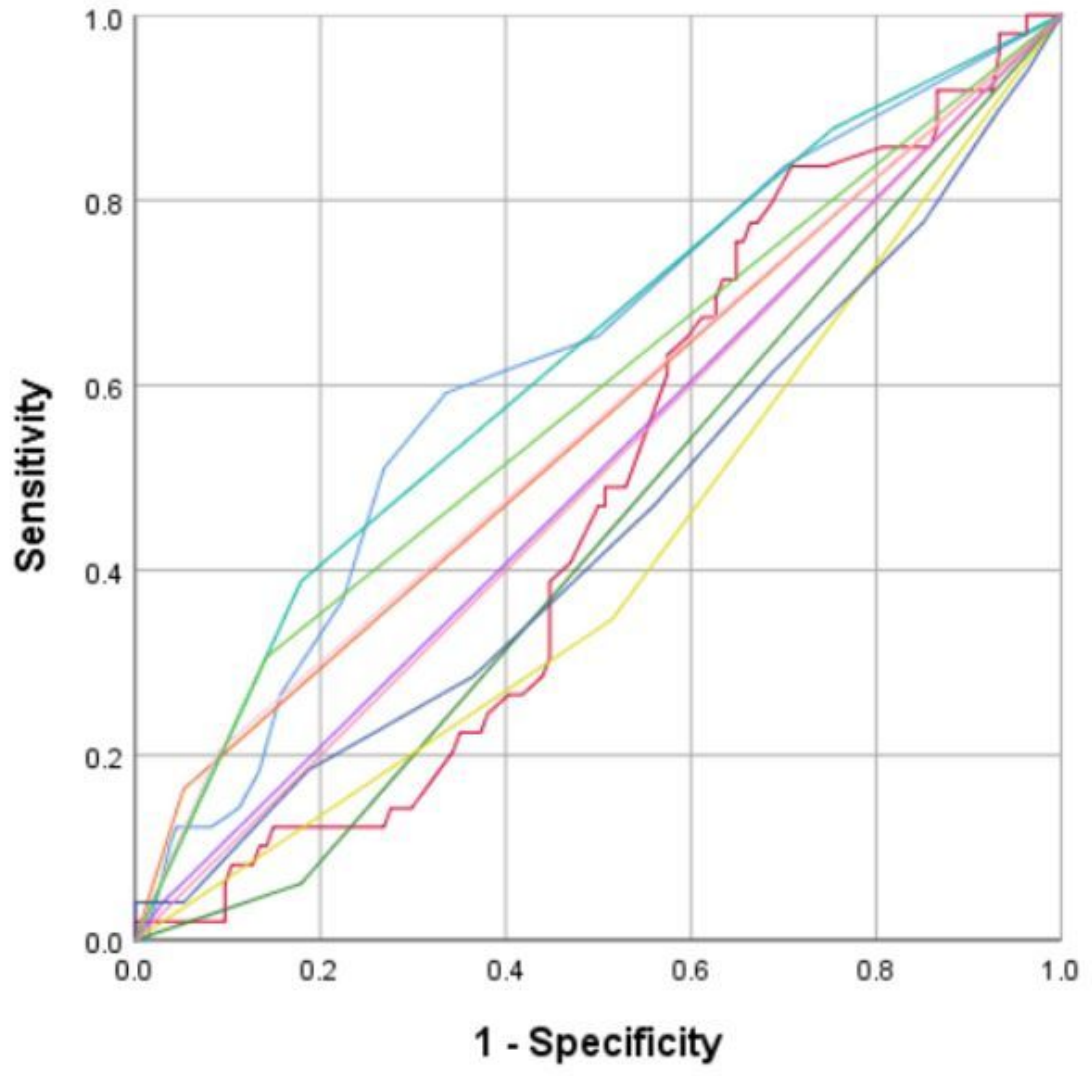

\section{Source of the Curve}

- Age

- Weight $(\mathrm{kg})$

- Race (NonBlack VS Black)

- Prior Tobacco Use

- Anterior Groin Tenderness

- Hop Test

Patellar Percussion Test

- Does Food Dominate Your Life Are You Satisfied with Your Eating Patterns

What Is Your Current Pain Level

Reference Line

Figure 2

Receiver Operator Characteristic Curves for Pool Variables 


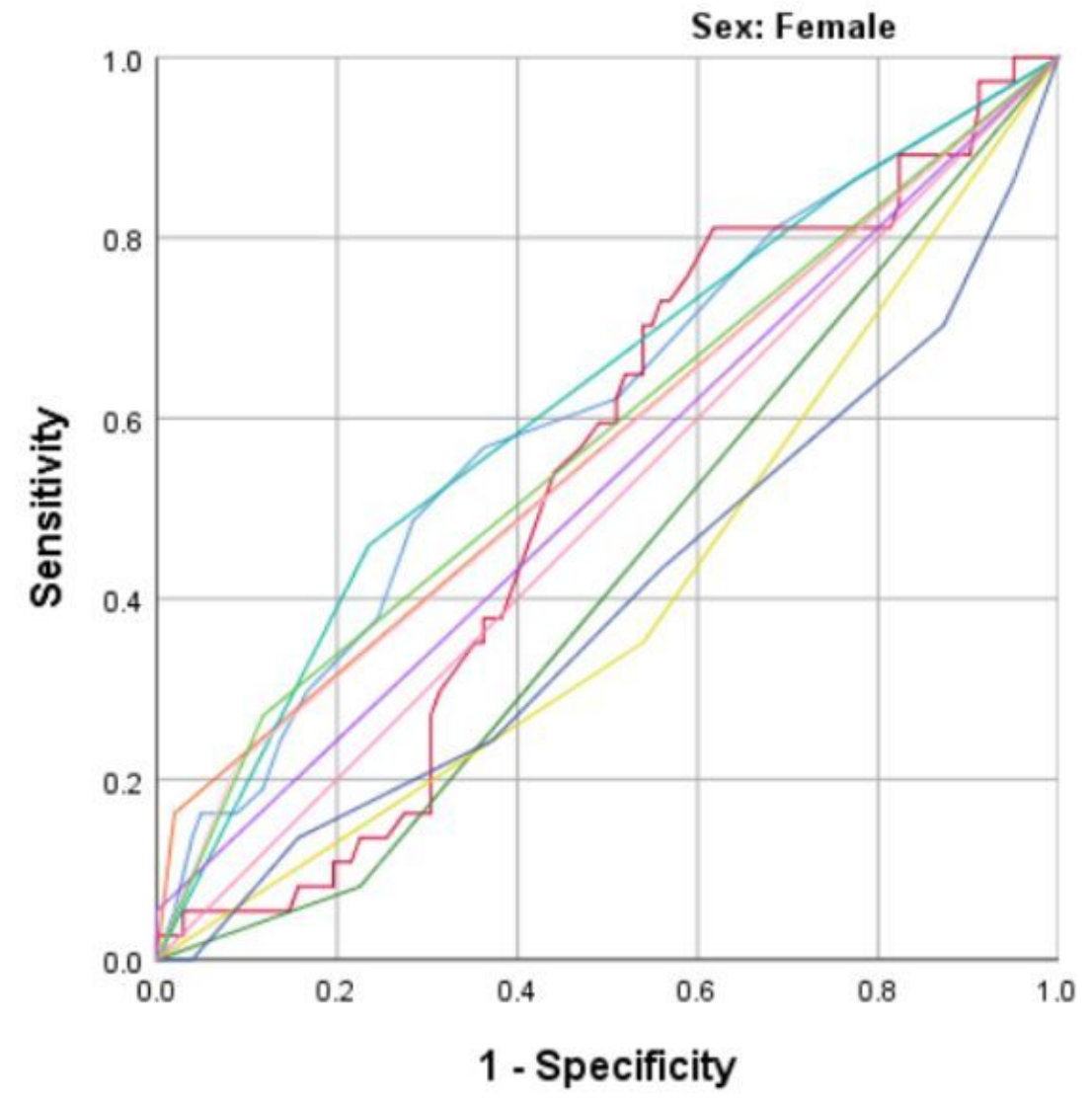

\section{Source of the Curve}

Age
Weight (kg)
Race (NonBlack VS Black)
Prior Tobacco Use
Anterior Groin Tenderness
Hop Test
Patellar Percussion Test
Does FOOD Dominate Your
Life
Are You Satisfied with Your
Eating Patterns
What Is Your Current Pain
Level
Reference Line

Figure 3

Receiver Operator Characteristic Curves for Female Gender-Split Variables 


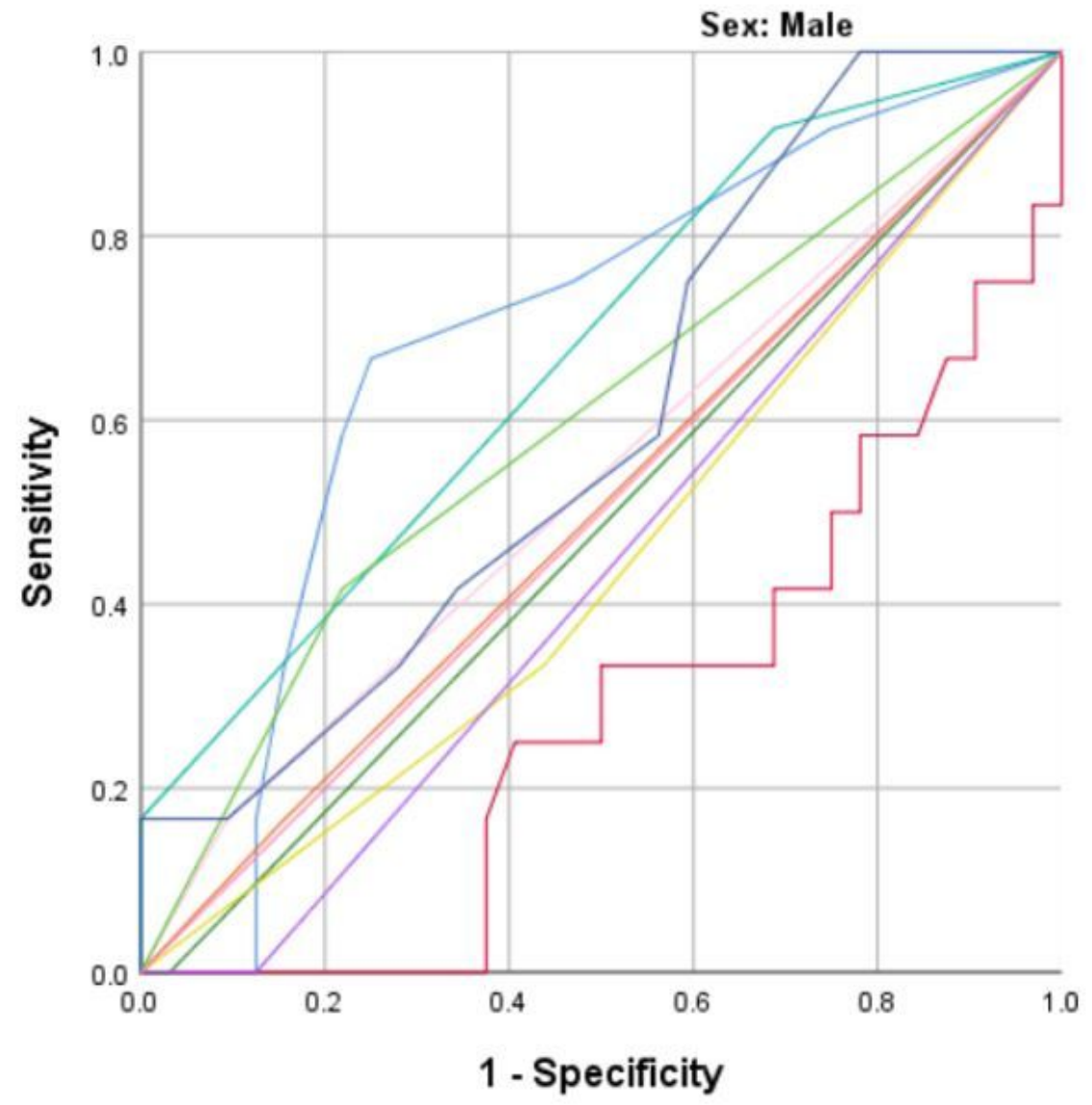

Source of the Curve

-Age

- Weight $(\mathrm{kg})$

_- Race (NonBlack VS Black)

- Prior Tobacco Use

Anterior Groin Tenderness

Hop Test

Patellar Percussion Test Does FOOD Dominate Your Life

Are You Satisfied with Your Eating Patterns What Is Your Current Pain Level

Reference Line

\section{Figure 4}

Receiver Operator Characteristic Curves for Male Gender-Split Variables

\section{Supplementary Files}

This is a list of supplementary files associated with this preprint. Click to download.

- Appendix1.docx

- Appendix2.docx 